\title{
Phytochemical Evaluation of Anti-Inflammatory Activity of Different Solvents Extracts of Ixora javanica Flowers
}

\section{Yerragunta Vishwanadham ${ }^{1 *}$, Sunitha $D^{2}$ and Ramesh $A^{1}$}

${ }^{1}$ Department of Pharmaceutical Chemistry, Vishni Institute of Pharmaceutical Education and Research, Narsapur, Medak District, Telangana, India ${ }^{2}$ Department of Pharmaceutical Chemistry, Malla Reddy College of Pharmacy, Secunderabad, Telangana, India

\begin{abstract}
Ixora javanica (Family Rubiaceae) commonly known as Red Ixora (Nooruvarahalu) in Telugu, Ixora javanica is an ornamental flowering shrub or small tree usually found in tropical south East Asia including southern India. It is mainly used for anti-cancer activity. This study was aimed at providing pharmacological basis for its use in inflammation. Based on this to evaluate the inflammatory activity of Ixora javanica flowers with their phyto constituents. Here using different solvent extract Ixora javanica flowers (Petroleum ether and Ethyl acetate). The Ethyl acetate extract of Ixora javanica flowers showed potent activity comparing with the standard drug diclofenac sodium perhaps due to presence of glycoside and flavonoids present in the flowers. Anti-inflammatory activity by using carrageenan-induced rat paw edema method results indicated that the different extracts of Ixora javanica. Ethyl acetate (EAIJ) extract of at dose of $200 \mathrm{mg} / \mathrm{kg}$ showed significant activity $(\mathrm{p}<0.01)$ reduction in paw volume, at dose of $200 \mathrm{mg} / \mathrm{kg}$ exhibited a marked $(P<0.05)$, inhibition of paw volume, which was comparable to diclofenac $(100 \mathrm{mg})$.
\end{abstract}

Keywords: Ethyl acetate; Petroleum ether; Carrageenan; Antiinflammatory activity

\section{Introduction}

Inflammation is a primary physiological defense mechanism which protects body from noxious or injurious stimuli, characterized by warmth, redness of the skin, pain, swelling and loss of function. There are several tissue factors that are known to be involved in the inflammatory reactions such as release of histamines, bradykinin and prostaglandins. Non-steroidal anti-inflammatory drugs (NSAIDs) produce intestinal tract ulcers (with potential internal bleeding) in 1030 percent of long-term users, and erosions of the stomach lining and intestinal tract in 30-50 percent of cases [1]. The new COX-2 inhibitor drugs have only been reported to reduce intestinal tract damage by 50 percent, and their toxicity to the liver and kidneys is still under review [2].

Ixora javanica (Family-Rubiaceae) commonly known as Red Ixora (Nooruvarahalu) in Telugu and Jungle flame Ixora in English. Ixora javanica is an ornamental flowering shrub or small tree usually found in tropical south East Asia including southern India. It is mainly used for anti-cancer activity. This study was aimed at providing pharmacological basis for its use in inflammation. Based on this to evaluate the inflammatory activity of Ixora javanica flowers with their phyto constituents.

\section{Materials and Methods}

\section{Collection of plant materials}

Ixora javanica flowers were collected and it was authenticated (No.01712) by Prathiba Devi, Department of Botany, Osmania University, Telangana, India (Figure 1). The Ixora javanica flowers ware collected and dried. These dried flowers were mechanically powdered, sieved using 80 size mesh and stored in an airtight container. This powdered material was used for phytochemical screening and antiinflammatory study.

\section{Preparation of extract}

The shade dried flowers of Ixora javanica (Rubiaceae) were subjected to fine powder and subjected to continuous successive extraction with different solvents based on polarity like pertoleum ether, ethyl acetate using soxhlet extractor. After complete extraction, solvents were distilled off and finally dried under reduced pressure and dryness in flash evaporator. The concentrate was suspended in $5 \% \mathrm{w} / \mathrm{v}$
Tween 80 and given at dose $1 \mathrm{ml} / 100$ gm body weight. The extracts of different solvents were tested for their pharmacological activity.

\begin{tabular}{c|c} 
Petroleum ether flower extract & Sterols, terpenoids \\
\hline Ethyl acetate flower extract & Flavonoids, terpenoids, glycosides \\
\hline
\end{tabular}

\section{Treatment of animals}

Using healthy validated animal models such as male wistar rats, 4-8 weeks rats were selected after physical and behavioral veterinary examination from Institutional Animal house of Malla Reddy College of Pharmacy. The weight range was fall within $20 \%$ of the mean body for each sex at the time of initiation of treatment. All experiments involving animals complies with the ethical standards of animal handling and approved by Institutional Animal ethics committee (CPCSEA).

Thirty adult male Wistar rats, weighing 120-150 g were obtained from the institutional animal house of Malla Reddy College of pharmacy. The rats were kept in polyethylene cages and allowed one week of acclimatization. Maintained on standard rat chow and standard laboratory.

\section{Phytochemical screening}

The concentrated extracts were used for preliminary screening of various phytochemical constituents like carbohydrate, amino acid, alkaloids, tannins and flavonoids were detected by usual methods prescribed in protocol of standard tests [3-5].

\section{Acute toxicity test}

Acute toxicity study was carried out as per OECD guidelines 425 (Acute toxicity class method) [6].

*Corresponding author: Yerragunta Vishwanadham, Department of Pharmaceutical Chemistry, Vishni Institute of Pharmaceutical Education and Research, Narsapur, Medak District, Telangana, India, Tel: +919704697309; E-mail: vishwanadham.y@gmail.com

Received March 31, 2016; Accepted April 21, 2016; Published April 28, 2016

Citation: Vishwanadham Y, Sunitha D, Ramesh A (2016) Phytochemical Evaluation of Anti-Inflammatory Activity of Different Solvents Extracts of Ixora javanica Flowers. Nat Prod Chem Res 4: 219. doi:10.4172/2329-6836.1000219

Copyright: () 2016 Vishwanadham Y, et al. This is an open-access article distributed under the terms of the Creative Commons Attribution License, which permits unrestricted use, distribution, and reproduction in any medium, provided the original author and source are credited. 
Citation: Vishwanadham Y, Sunitha D, Ramesh A (2016) Phytochemical Evaluation of Anti-Inflammatory Activity of Different Solvents Extracts of Ixora javanica Flowers. Nat Prod Chem Res 4: 219. doi:10.4172/2329-6836.1000219

Page 2 of 3

\section{Anti-inflammatory activity}

Validated models the male wistar rats appropriately body weight between 120-150 g were used. The animals were starved overnight at least 18 hours prior to the experiment. The animals were divided randomly in five groups with six rats per each group as follows-Group I- control, Group II- standard i.e., diclofenac sodium $(100 \mathrm{mg} / \mathrm{kg}$, p.o.), Group III- PEIJ (100 mg/kg, p.o.), Group IV- EAIJ (100 mg/kg, p.o.) and Group V- PEIJ (200 mg/kg), EAIJ (200 mg/kg) [7-9]. After selection of animal $0.1 \mathrm{ml}$ of $1 \%$ carrageenan solution was injected into the left hind paw. The pre-treatment time was $1 \mathrm{hr}$. before carrageenan injection. The volume of the paw was measured with the help of digital plethysmometer at $0,15 \mathrm{~min}, 30 \mathrm{~min}, 1 \mathrm{~h}, 2 \mathrm{~h}$ and $4 \mathrm{~h}$. (UGO Basile 7140). The results are tabulated by percent of inhibition [10-12].

\section{Statistical analysis}

All the values were statistically analyzed by one-way analysis of variance (ANOVA) [13] followed by multiple comparison test. Comparison between control and drug treated groups were considered to be significant $\mathrm{P}<0.01, \mathrm{P}<0.001$. All values are expressed as Mean $\pm \mathrm{SEM}$.

\section{Results}

Anti-inflammatory activity of pertoleum ether and ethyl acetate extracts of Ixora javanica flowers in carrageenan induced paw edema (Table 1). Anti-inflammatory activity of petroleum ether and ethyl acetate extracts of Ixora javanica \% inhibition of paw volume (Table 2). Anti-inflammatory activity of pertoleum ether and ethyl acetate extracts of Ixora javanica flowers in carrageenan induced paw oedema (Graph 1). Anti-inflammatory activity of pertoleum ether and ethyl acetate extracts of Ixora javanica \% inhibition of paw volume (Graph 2).

\section{Acute toxicity studies}

The extracts of Ixora javanica flowers did not show any sign of toxicity up to $2000 \mathrm{mg} / \mathrm{kg}$ body weight and hence it was considered to be safe.

\section{Phytochemical studies}

The phytochemical analysis showed that the solvent extracts contained presence of flavonoids, glycosides, terpenoids, and steroids.

\section{Anti-inflammatory study}

Ixora javanica flowers extraction of different solvents were evaluated for Anti-inflammatory activity using carrageenan induced paw edema, Ethyl acetate extract administered intraperitoneally produced a significant anti-inflammatory activity in a dose-dependent manner respectively in the rats (Tables 1 and 2).

\section{Discussion}

Ixora javanica of the family Rubiaceae is a common plant of south East Asia including southern India. Phytochemical evaluation of the pertoleum ether and ethyl acetate extracts of Ixora javanica flowers reveals the presence of flavonoids, carbohydrate, tannins and alkaloids. Here anti-inflammatory activity was performed based on the folk lore information using rat paw oedema method [14].

Ethyl acetate extract of Ixora javanica flowers showed significant anti-inflammatory activity. This significant anti-inflammatory effect may be due to the inhibition of any inflammatory mediators by the terpenoids, flavonoids present in the extract. The present result indicates the efficacy of Ixora javanica as an effective therapeutic agent in the treatment of acute inflammations. The result of present study on the anti-inflammatory property of the flowers extract of Ixora javanica. Ethyl acetate (EAIJ) extract of at dose of $200 \mathrm{mg} / \mathrm{kg}$ showed significant activity $0.017 \pm 0.0003^{* *}$ and $\%$ inhibition of paw volume $62 \%$.

Further and detailed studies are in process for the isolation of active constituent responsible for this property and to identification of the possible mechanism of its anti-inflammatory property.

Statistical analysis was done by ANOVA followed by Dunnet's test. All the values are expressed as mean \pm SEM. ${ }^{\star} \mathrm{P}<0.05,{ }^{* \star} \mathrm{P}<0.01$.

\section{Conclusion}

The results suggest that the ethyl acetate extract of Ixora javanica flowers showed potent activity comparing with the standard drug

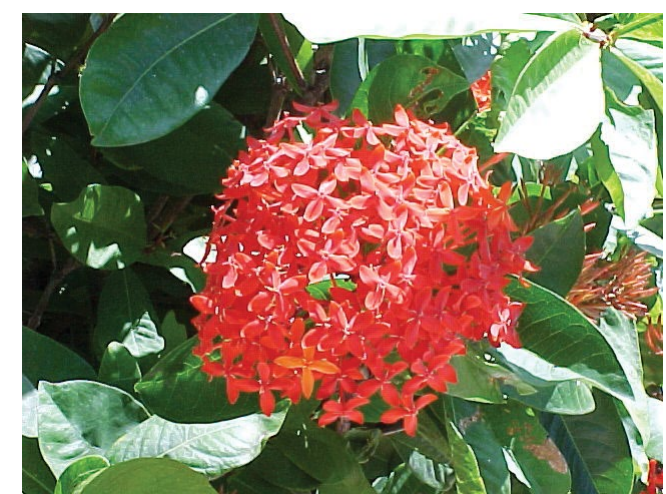

Figure 1: Picture showing the Ixora javanica Flowers.

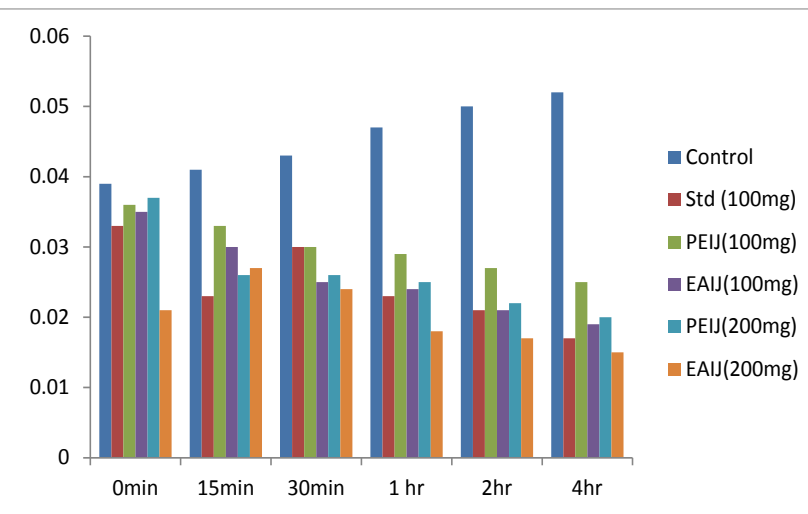

Graph 1: Anti-inflammatory activity of Petroleum ether and Ethyl acetate extracts of Ixora javanica flowers in carrageenan induced paw oedema.

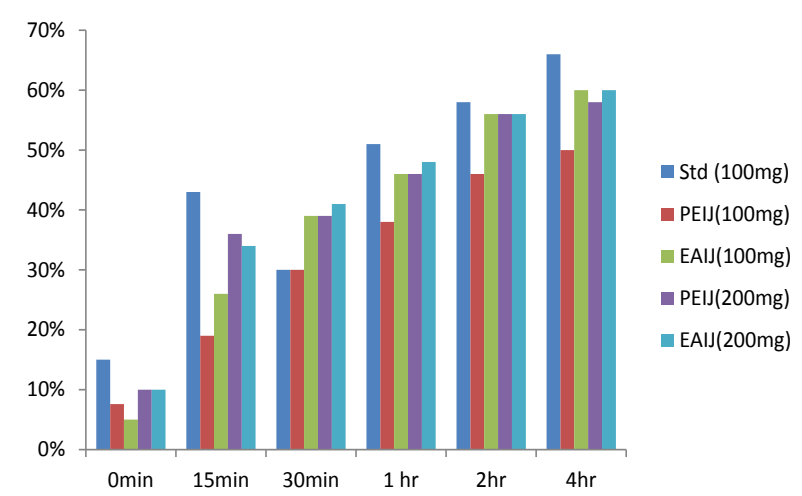

Graph 2: Anti-inflammatory activity of Petroleum ether and Ethyl acetate extracts of Ixora javanica \% inhibition of paw volume. 
Citation: Vishwanadham Y, Sunitha D, Ramesh A (2016) Phytochemical Evaluation of Anti-Inflammatory Activity of Different Solvents Extracts of Ixora javanica Flowers. Nat Prod Chem Res 4: 219. doi:10.4172/2329-6836.1000219

Page 3 of 3

\begin{tabular}{|c|c|c|c|c|c|c|c|}
\hline & Dose (mg/kg) & $0 \mathrm{~min}$ & $15 \mathrm{~min}$ & $30 \mathrm{~min}$ & $1 \mathrm{hr}$. & $2 \mathrm{hr}$. & $4 \mathrm{hr}$. \\
\hline Control & & $0.039 \pm 0.0001$ & $0.041 \pm 0.0003$ & $0.043 \pm 0.0001$ & $0.047 \pm 0.0001$ & $0.050 \pm 0.0004$ & $0.052 \pm 0.0007$ \\
\hline Standard & 100 & $0.033 \pm 0.0001^{*}$ & $0.025 \pm 0.0002^{* *}$ & $0.023 \pm 0.0001^{* *}$ & $0.022 \pm 0.0001^{* *}$ & $0.021 \pm 0.0008^{* *}$ & $0.017 \pm 0.0003^{* *}$ \\
\hline PEIJ & 100 & $0.036 \pm 0.0001^{*}$ & $0.033 \pm 0.0004^{*}$ & $0.030 \pm 0.0004^{*}$ & $0.029 \pm 0.0001^{*}$ & $0.027 \pm 0.0009^{* *}$ & $0.025 \pm 0.0005^{\star *}$ \\
\hline EAIJ & 100 & $0.035 \pm 0.0001^{*}$ & $0.030 \pm 0.0001^{* *}$ & $0.025 \pm 0.0001^{* *}$ & $0.024 \pm 0.0001^{* *}$ & $0.021 \pm 0.0001^{* *}$ & $0.019 \pm 0.0004^{* *}$ \\
\hline PEIJ & 200 & $0.037 \pm 0.0001^{*}$ & $0.026 \pm 0.0001^{* *}$ & $0.026 \pm 0.0001^{* *}$ & $0.025 \pm 0.0001^{* *}$ & $0.022 \pm 0.0001^{* *}$ & $0.020 \pm 0.0003^{* *}$ \\
\hline EAIJ & 200 & $0.027 \pm 0.0004^{*}$ & $0.024 \pm 0.0003^{* *}$ & $0.021 \pm 0.0007^{* *}$ & $0.019 \pm 0.0003^{* *}$ & $0.018 \pm 0.0003^{* *}$ & $0.017 \pm 0.0003^{* *}$ \\
\hline
\end{tabular}

Statistical analysis was done by ANOVA followed by Dunnet's test. All the values are expressed as mean $\pm \mathrm{SEM}$. ${ }^{\mathrm{P}} \mathrm{P}<0.05$, " $\mathrm{P}<0.01$.

Table 1: Anti-inflammatory activity of Petroleum ether and Ethyl acetate extracts of Ixora javanica flowers in carrageenan induced paw edema.

\begin{tabular}{|c|c|c|c|c|c|c|c|}
\hline & Dose $\mathbf{( m g} / \mathbf{k g})$ & $\mathbf{0} \mathbf{~ m i n}$ & $\mathbf{1 5} \mathbf{~ m i n}$ & $\mathbf{3 0} \mathbf{~ m i n}$ & $\mathbf{1} \mathbf{h r}$ & $\mathbf{2} \mathbf{h r}$ & $\mathbf{4} \mathbf{h r}$ \\
\hline Standard & 100 & $15 \%$ & $43 \%$ & $30 \%$ & $51 \%$ & $58 \%$ & $66 \%$ \\
\hline PEIJ & 100 & $7.6 \%$ & $19 \%$ & $30 \%$ & $38 \%$ & $46 \%$ & $50 \%$ \\
\hline EAIJ & 100 & $5 \%$ & $26 \%$ & $39 \%$ & $46 \%$ & $56 \%$ & $60 \%$ \\
\hline PEIJ & 200 & $10 \%$ & $36 \%$ & $39 \%$ & $46 \%$ & $56 \%$ & $58 \%$ \\
\hline EAIJ & 200 & $10 \%$ & $34 \%$ & $41 \%$ & $48 \%$ & $58 \%$ & $62 \%$ \\
\hline
\end{tabular}

4. Trease GE, Evans WC (2009) Pharmacognosy. 16th edn. London: Bailliere Tindall Ltd. pp: 60-75.

5. Shreedhara CS, Vaidya VP, Vagdevi HM, Latha KP, Muralikrishna KS et al. (2009) Screening of Bauhinia purpurea Linn. for analgesic and antiinflammatory activities. Indian J Pharmacol 41: 75-79.

6. Mangesh BS, Virendra KG, Rohini PR, Vivek PB, Hardik HA (2011) Therapeutic effect of a poly-herbal preparation on adjuvant induced arthritis in wistar rats. International Journal of Pharmacy \& Pharmaceutical Sciences 2: 1520-1527.

Statistical analysis was done by ANOVA followed by Dunnet's test. All the values are expressed as mean \pm SEM. ${ }^{*} \mathrm{P}<0.05$; ${ }^{*} \mathrm{P}<0.01$

Table 2: Anti-inflammatory activity of Petroleum ether and Ethyl acetate extracts of Ixora javanica \% inhibition of paw volume.

diclofenac sodium perhaps due to presence of glycoside and flavonoids present in the flowers. Anti-inflammatory activity by using carrageenaninduced rat paw edema method results indicated that the different extracts of Ixora javanica. Ethyl acetate (EAIJ) extract of at dose of 200 $\mathrm{mg} / \mathrm{kg}$ showed significant activity $(\mathrm{p}<0.01)$ reduction in paw volume, at dose of $200 \mathrm{mg} / \mathrm{kg}$ exhibited a marked $(\mathrm{P}<0.05)$, inhibition of paw volume, which was comparable to diclofenac $(100 \mathrm{mg})$.

\section{References}

1. Hayllar J, Macpherson A, Bjarnason I (1992) Gastroprotection and nonsteroidal anti-inflammatory drugs (NSAIDS). Rationale and clinical implications. Drug Saf 7: 86-105.

2. Ament PW, Childers RS (1997) Prophylaxis and treatment of NSAID-induced gastropathy. Am Fam Physician 55: 1323-1326.

3. Amin Mir M, Sawhney SS, Jassal Wudpecker MMS (2013) Qualitative and quantitative analysis of phytochemicals of Taraxacum officinale. Journal of Pharmacy and Pharmacology 2: 001-005.

7. Shripad BM, Abhijeet AA, Inayat PB, Nitin N (2012) Analgesic and AntiInflammatory Evaluation of Ficus Microcarpa L. Leaves Extract. Asian Journal of Pharmaceutical \& Clinical Research 2: 953-961.

8. Vinay J, Panigrahi F (2012) Anti-Inflammatory and Analgesic Activity of Arisaema leschenaultia Blume. Journal of Pharmacy Research 5.

9. Acute Oral Toxicity (AOT) (OECD Test Guideline 425) Statistical Programme (AOT425StatPgm) (2001) OECD guideline for testing of chemicals. Version: 1.0 .

10. Crunkhorn $\mathrm{P}$, Meacock SC (1971) Mediators of the inflammation induced in the rat paw by carrageenin. $\mathrm{Br} \mathrm{J}$ Pharmacol 42: 392-402.

11. Vinegar R, Schreiber W, Hugo R (1969) Biphasic development of carrageenin edema in rats. J Pharmacol Exp Ther 166: 96-103.

12. Winter CA, Risley EA, Nuss GW (1962) Carrageenin-induced edema in hind paw of the rat as an assay for antiiflammatory drugs. Proc Soc Exp Biol Med 111: 544-547.

13. Castro JA, Sasame HA, Sussman H, Gillette JR (1968) Diverse effects of SKF 525-A and antioxidants on carbon tetrachloride-induced changes in liver microsomal P-450 content and ethylmorphine metabolism. Life Sci 7: 129-136.

14. Chawla AS, Singh M, Murthy MS, Gupta M, Singh H (1987) Anti-inflammatory action of ferulic acid and its esters in carrageenan induced rat paw oedema model. Indian J Exp Biol 25: 187-189. 